\title{
Mapping Global Risk of GDP Loss to River Floods
}

\author{
Junlin Zhang, Xinli Liao, and Wei Xu
}

\section{Background}

Globally, river flooding induced by heavy rainfall frequently causes serious economic losses every year (Jongman et al. 2015; CRED and UNISDR 2018; CRED 2019). Particularly, heavy rainfall will increase in the future with climate warming (Liao et al. 2019). This could lead to greater rain-induced local flooding in some watersheds or regions (IPCC 2012). Besides, exposed assets to floods are increasing with the socioeconomic development (Jongman et al. 2015; Winsemius et al. 2018; Liao et al. 2019).

Generally, river flooding risk assessment has two steps. The first is to simulate river flooding hazard using hydrological or hydrodynamic model and inundation model, and the second is to calculate economic losses by overlaying the economic data and flood hazard maps, and the results are used to assess the economic loss risks from floods (Arnell and Gosling 2016; Lim et al. 2018). Projected future precipitation and social-economic datasets provide a basis for these studies. Vulnerability functions of economic loss have been developed for the risk assessment (Alfieri et al. 2015; Muis et al. 2015; Dottori et al. 2016; Sarhadi et al. 2016; Wing et al. 2018). But most studies are concerned with asset losses and there are few studies on GDP loss risks. In addition, many studies focus on the risk at the country and

Authors: Junlin Zhang, Xinli Liao, Wei Xu.

Map Designers: Junlin Zhang, Jing'ai Wang, Ying Wang.

Language Editor: Wei Xu.

J. Zhang $\cdot$ X. Liao $\cdot$ W. Xu ( $₫)$

Institute of Disaster Risk Science, Beijing Normal University,

Beijing, 100875, China

e-mail: xuwei@bnu.edu.cn

W. Xu

State Key Laboratory of Earth Surface Processes and Resource

Ecology, Beijing Normal University, Beijing, 100875, China region levels, lacking grid-level high spatial resolution results.

In order to address the issues, this study assessed the GDP loss risks from floods by two main steps. The first was to develop vulnerability functions of GDP losses for the countries by revising an existing vulnerability function. Then future potential GDP losses of the 2030s and the 2050s were estimated at the $2.5^{\prime}$ grid level under the Representative Concentration Pathway (RCP) and Shared Socioeconomic Pathway (SSP) scenarios of RCP4.5-SSP2 and RCP8.5-SSP3. The results were compiled to produce the risk maps at the $0.25^{\circ}$ grid level and country level.

\section{Method}

Figure 1 shows the technical flowchart for mapping the risk of GDP loss to floods of the world. This study revised the existing vulnerability functions by adjustment coefficient that is calculated based on recorded GDP losses. Then future losses were estimated using predicted inundation data and GDP data, and the adjusted vulnerability functions. Future losses at the grid level were then aggregated to other geographic units. Finally, the risk size and model uncertainty are analyzed.

\subsection{Estimation of Risks}

\subsubsection{Estimation of Losses for the Baseline Period}

The vulnerability function of asset losses is represented by Eq. (1) (Wing et al. 2018). Using the function, historical asset losses were estimated by Eqs. (2) and (3). 


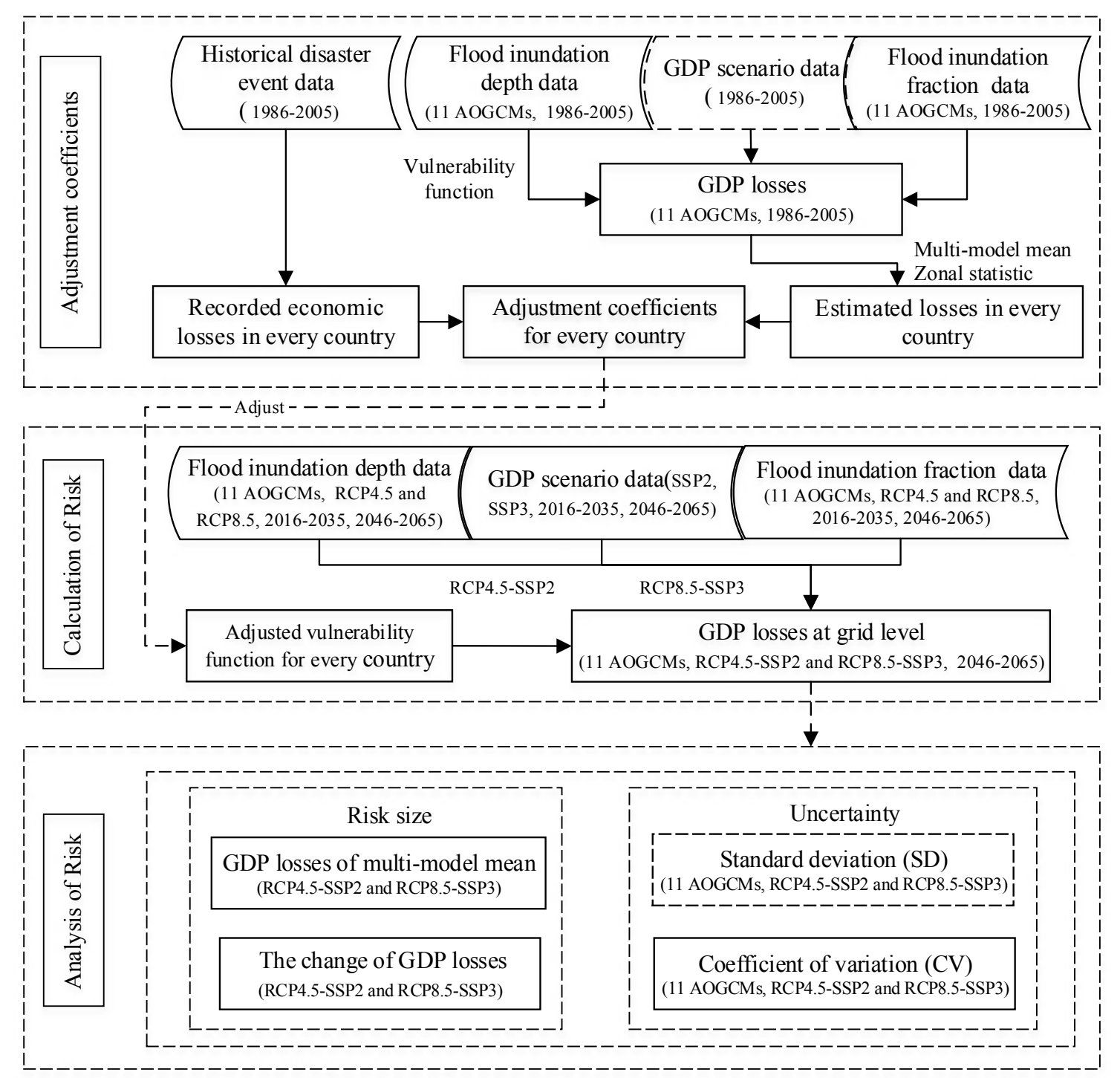

Fig. 1 Technical flowchart for mapping global risk of GDP loss to river floods. AOGCM = Atmosphere-Ocean General Circulation Model; RCP = Representative Concentration Pathway; SSP = Shared Socioeconomic Pathway

$$
\begin{gathered}
V(d)=\left\{\begin{array}{r}
-0.0067 d^{4}+0.0723 d^{3}-0.233 d^{2}+0.3953 d, d<5 \\
0.0038 d+0.962, d \geqslant 5
\end{array}\right. \\
L_{h i s \_i \_j}=V\left(d_{h i s \_i \_j}\right) \times S_{h i s \_j} \times f_{h i s \_i \_j} \\
L_{h i s}=\frac{1}{11 \times 20} \sum_{j=1}^{20} \sum_{i=1}^{11} L_{h i s \_i \_j}
\end{gathered}
$$

where $i$ is the order of the 11 Atmosphere-Ocean General Circulation Models (AOGCMs); $j$ is the sequence of the 20 years; his is the baseline period (1986-2005); $L_{\text {his } \_i \_j}$, $d_{\text {his } \_i_{j},}$, and $f_{\text {his } \_i_{j} j}$ are the estimated losses, water depth, and inundation fraction for the $i$ th AOGCM in the $j$ th year for the baseline period, respectively; $S_{\text {his } \_j}$ is the GDP data in the $j$ th year of the baseline period; $L_{\mathrm{his}}$ is the annual average loss, that is multi-model ensemble for the baseline period; $V(d)$ is the vulnerability function.

\subsubsection{Calculation of Adjustment Coefficients}

The study revised the vulnerability function of asset loss (Eq. 1) for countries to build the vulnerability function of GDP loss. Using Eq. (4), the adjustment coefficients $\left(K_{c}\right.$ values) were calculated for the countries with total recorded 
losses and estimated losses both greater than zero during the baseline period. On this basis, the adjustment coefficient is the minimum of above calculated $K_{c}$ values for the countries with total recorded losses equal to zero during the baseline period; and the adjustment coefficient is the average of above calculated $K_{c}$ values for the countries with total recorded losses greater than zero but total estimated losses equal to zero.

$$
K_{c}=\frac{\sum_{j=1}^{20} S L_{h i s \_c \_j}}{L_{h i s \_c}}
$$

where $K_{c}$ is the adjustment coefficient of country $c ; j$ represents the sequential number of the 20 years in the baseline period; $S L_{\text {his } \_c \_j}$ is the recorded direct economic losses of country $c$.

The adjusted vulnerability function is shown in Eq. (5).

$$
\operatorname{Adj} V_{c}(d)=K_{c} \times V(d)
$$

where $\operatorname{Adj} V_{c}(d)$ is the adjusted vulnerability function of country $c$.

\subsubsection{Calculation of Future Losses and Change}

Future losses of a grid in country $c$ were estimated according to Eq. (6), based on future predicted inundation and GDP data and the adjusted vulnerability function. Next, the study averaged the results of 20 years for all AOGCMs (Eq. 7) to compute uncertainties; then we averaged the results of the 11 AOGCMs as the losses of the 2030s or the 2050s to reduce model uncertainties (Eq. 8). Finally, the changes of losses from the baseline period to the future period were calculated by Eq. (9).

$$
L_{f u t \_i \_j}=\operatorname{Adj} V_{c}\left(d_{f u t \_i \_j}\right) \times S_{f u t \_j} \times f_{f u t \_i \_j}
$$

where $L_{\text {fut } \_i_{j} j}, d_{\text {fut } \_i_{-} j}$, and $f_{\text {fut } \_i_{j} j}$ are the estimated GDP losses, water depth, and inundation fraction for the $i$ th AOGCM in the $j$ th year for a future period, respectively; $S_{\text {fut } j}$ is the GDP data in the $j$ th year of a future period.

$$
L_{f u t \_i}=\frac{1}{20} \sum_{j=1}^{20} L_{f u t \_i \_j}
$$

where $L_{f u t \_}$is the average losses of 20 years $(2016-2035$ or 2046-2065) for the $i$ th AOGCM.

$$
L_{f u t}=\frac{1}{11} \sum_{i=1}^{11} L_{f u t \_i}
$$

where $L_{\text {fut }}$ is the losses of the 2030s or the 2050s for the multi-model ensemble, which averaged the results from the 11 AOGCMs.

$$
\Delta L=L_{f u t}-L_{h i s}
$$

where $\Delta L$ is the change of losses for the 2030s or the 2050 s relative to the baseline period.

\subsection{Model Uncertainty}

The result uncertainty of multi-models is measured by standard deviation (Eq. 10) and coefficient of variation CV, the ratio of $S D$ to $L$ in Eq. 10.

$$
S D=\sqrt{\frac{\sum_{i=1}^{11}\left(L_{i}-L\right)^{2}}{11}}
$$

where $L_{i}$ is the average losses of 20 years for the $i$ th $\operatorname{AOGCM}\left(L_{\mathrm{his} \_} i\right.$ or $\left.L_{\text {fut } \_i}\right)$. $L$ is the average losses of 20 years for the multi-model ensemble ( $L_{\text {his }}$ or $\left.L_{\text {fut }}\right)$.

\section{Results}

Globally, the annual average GDP losses of the 2030s are approximately USD 223 billion for the RCP4.5-SSP2 scenario and USD 199 billion for the RCP8.5-SSP3 scenario; they increase 4.82 and 4.19 times relative to the baseline period, respectively. The annual average GDP losses of the 2050s are approximately USD 447 billion for the RCP4.5-SSP2 scenario and USD 429 billion for the RCP8.5-SSP3 scenario; they increase 10.69 and 10.21 times relative to the baseline period. The patterns of spatial distribution are similar for different scenarios. High-risk areas are mainly located in East Asia, South Asia, and Southeast Asia. The risks of GDP loss are the highest in the eastern coastal areas of China, the vicinity of the Ganges River Basin, and the coastal areas of the Indo-China Peninsula. Overall, the risk of the 2050s is higher than that of the 2030s. For Africa, the risks are higher in the western, southern, and eastern Africa. For South America, the risks are higher in Liano Orinoco Plain and La Plata Plain. The high-risk areas in Europe are spread out. The high-risk areas in North America are distributed in Atlantic Coastal Plain, along Saint Lawrence River, and in the southern coastal area. 


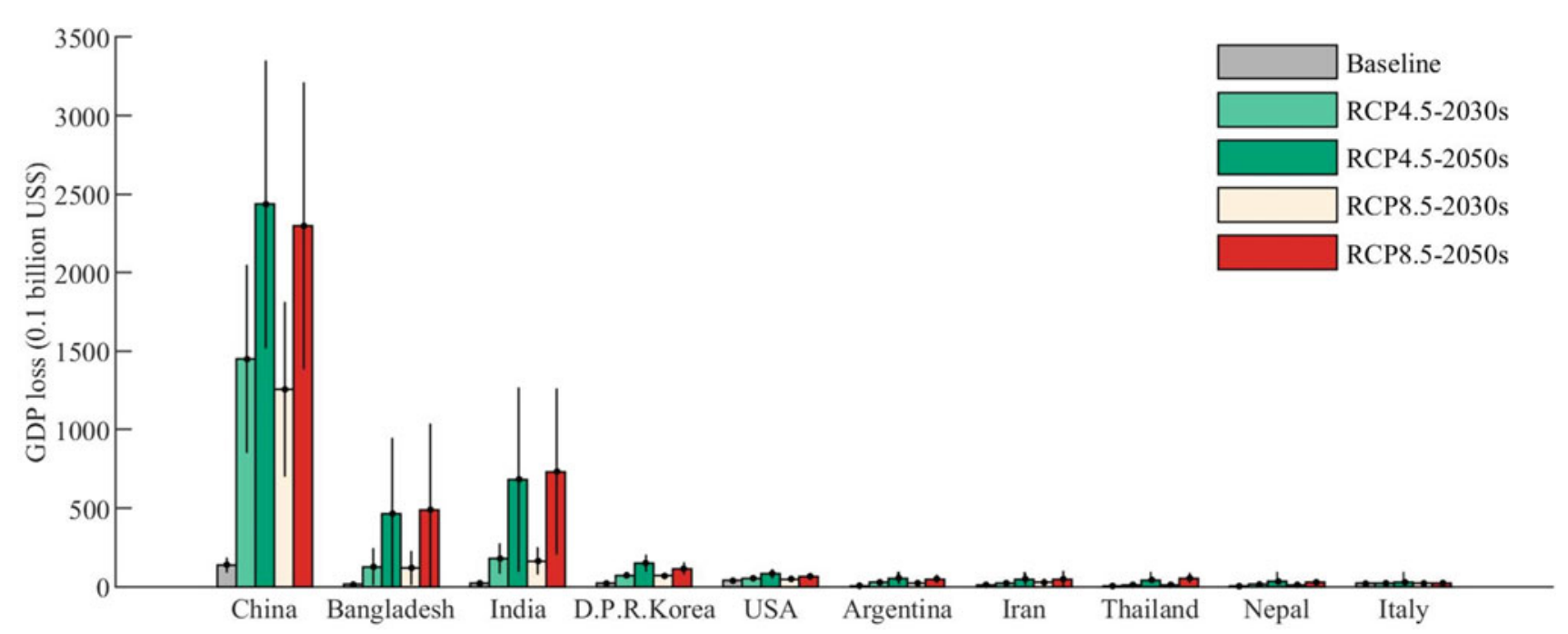

Fig. 2 Annual average GDP losses of the top 10 high-risk countries (in descending order by GDP loss). The error bar represents the standard deviations across 11 Atmosphere-Ocean General Circulation Models (AOGCMs)

The high-risk areas in Australia are mainly in the southeast coastal area.

By zonal statistics of the GDP loss results, we calculated the annual average GDP losses at the national level. Figure 2 shows the annual average GDP losses and errors (measured by standard deviation) of the top ten high-risk countries. The GDP loss risks are the highest for China, higher than
USD 100 billion for the 2030s and the 2050s, increasing more than eight times relative to the baseline period. The average annual GDP losses of the remaining countries are all lower than USD 100 billion. The changes are greater for India and Bangladesh relative to the baseline period. In most countries, the risks are higher in the 2050s than in the 2030s. 


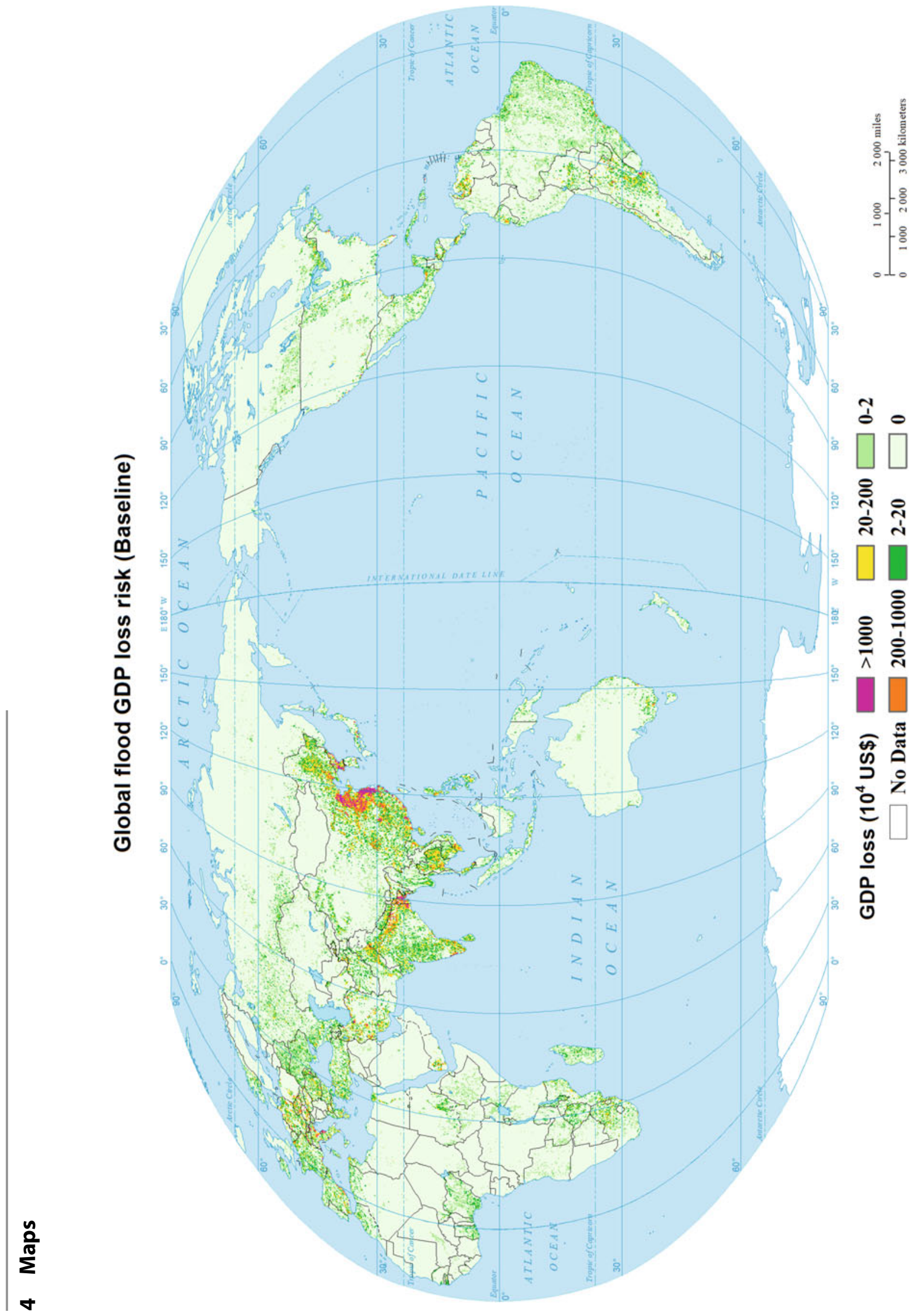



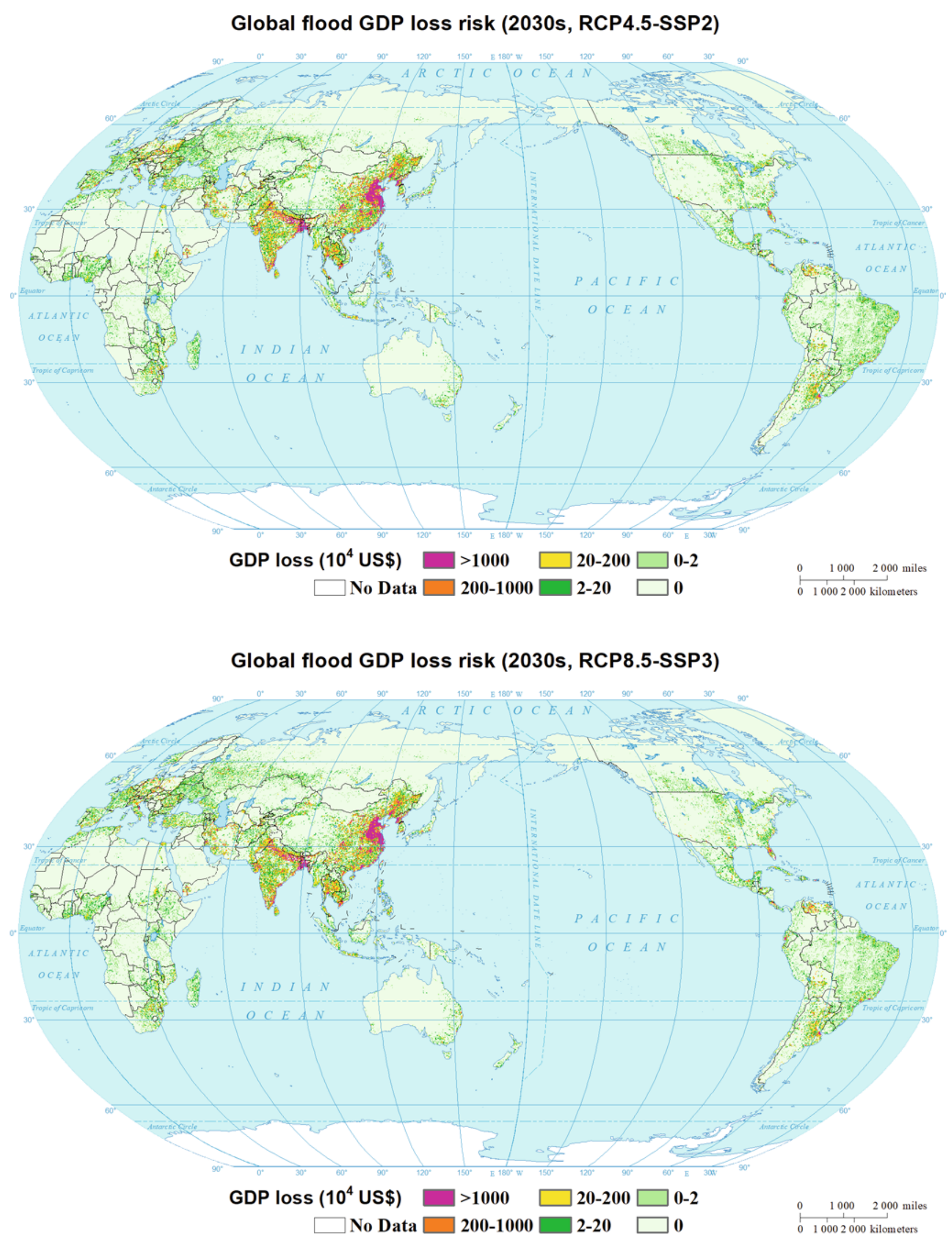


\section{Global flood GDP loss risk (2050s, RCP4.5-SSP2)}

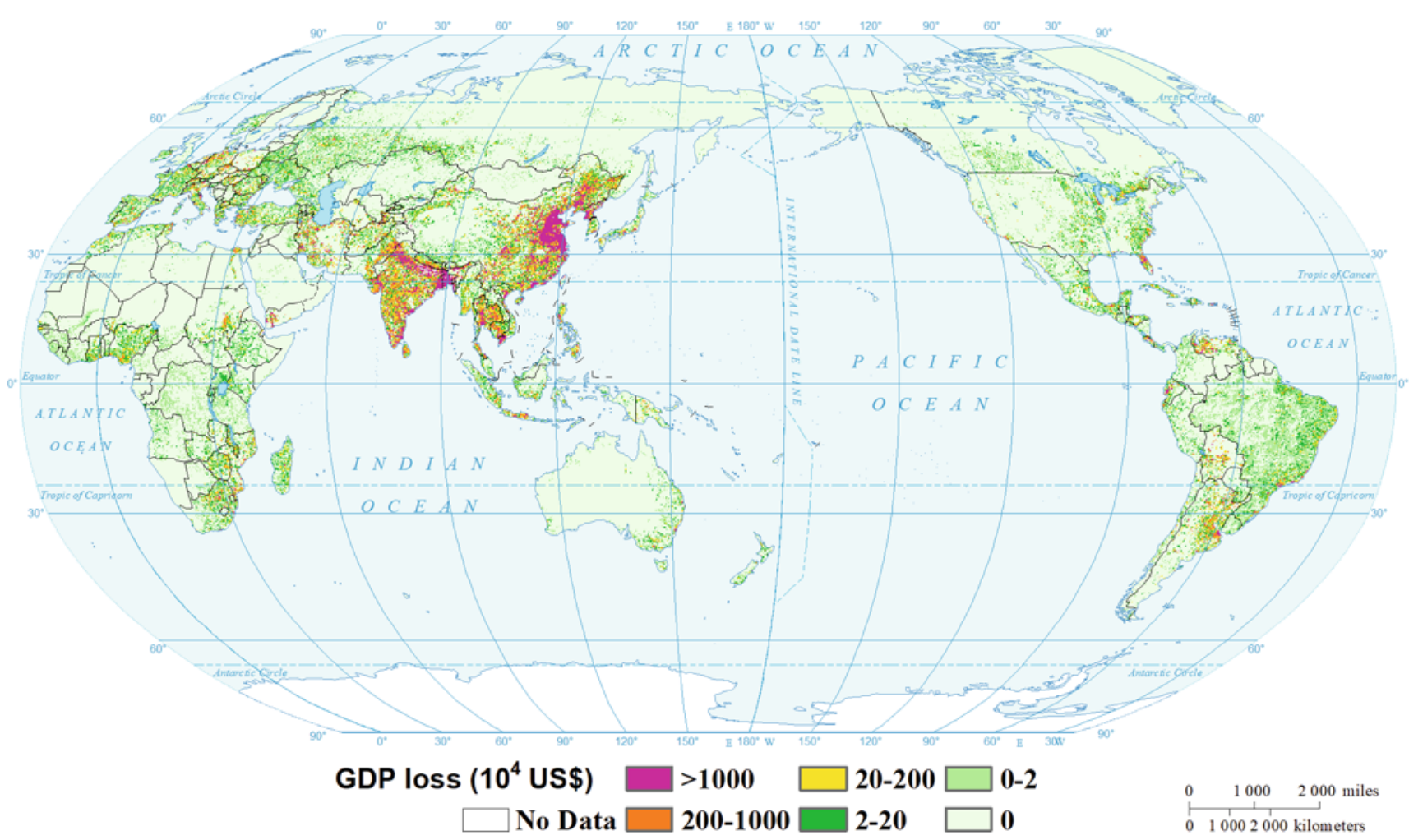

Global flood GDP loss risk (2050s, RCP8.5-SSP3)

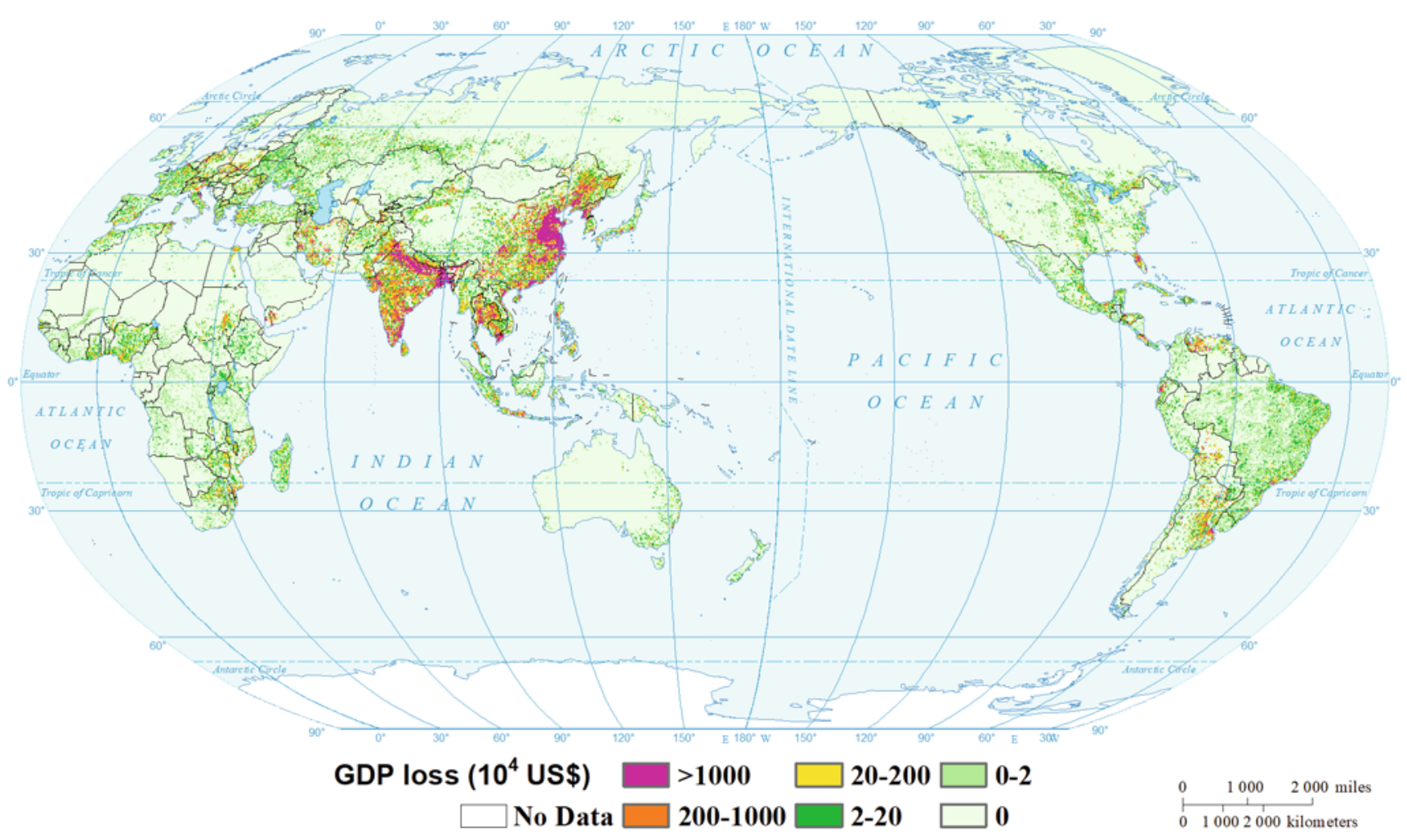




\section{References}

Alfieri, L., L. Feyen, F. Dottori, and A. Bianchi. 2015. Ensemble flood risk assessment in Europe under high end climate scenarios. Global Environmental Change 35: 199-212.

Arnell, N.W., and S.N. Gosling. 2016. The impacts of climate change on river flood risk at the global scale. Climatic Change 134 (3): 387-401.

CRED (Centre for Research on the Epidemiology of Disasters). 2019. 2018 Review of Disaster Events. Brussels, 24 January 2019. https:// www.emdat.be/publications.

CRED (Centre for Research on the Epidemiology of Disasters) and UNISDR (United Nations International Strategy for Disaster Reduction). 2018. Economic Losses, Poverty \& Disaster (19982017). https://www.emdat.be/publications.

Dottori, F., P. Salamon, A. Bianchi, L. Alfieri, F.A. Hirpa, and L. Feyen. 2016. Development and evaluation of a framework for global flood hazard mapping. Advances in Water Resources 94: 87102.

IPCC (Intergovernmental Panel on Climate Change). 2012. Managing the Risks of Extreme Events and Disasters to Advance Climate Change Adaptation. A Special Report of Working Groups I and II of the Intergovernmental Panel on Climate Change, ed. C.B. Field, V. Barros, T.F. Stocker, D. Qin, D.J. Dokken, K.L. Ebi, M.D. Mastrandrea, K.J. Mach, et al. Cambridge, UK: Cambridge University Press.

Jongman, B., H.C. Winsemius, J.C.J.H. Aerts, E.C. De Perez, M. Van Aalst, W. Kron, and P.J. Ward. 2015. Declining vulnerability to river floods and the global benefits of adaptation. Proceedings of the National Academy of Sciences of the United States of America 112 (18): 201414439.

Liao, X., W. Xu, J. Zhang, Y. Li, and Y. Tian. 2019. Global exposure to rainstorms and the contribution rates of climate change and population change. Science of the Total Environment 663: 644-653.

Lim, W.H., D. Yamazaki, S. Koirala, Y. Hirabayashi, S. Kanae, S. J. Dadson, J.W. Hall, and F.B. Sun. 2018. Long-term changes in global socioeconomic benefits of flood defenses and residual risk based on CMIP5 climate models. Earth's Future 6 (7): 938-954.

Muis, S., B. Guneralp, B. Jongman, J.C. Aerts, and P.J. Ward. 2015. Flood risk and adaptation strategies under climate change and urban expansion: a probabilistic analysis using global data. Science of the Total Environment 538: 445-457.

Sarhadi, A., M.C. Ausin, and M.P. Wiper. 2016. A new time-varying concept of risk in a changing climate. Scientific Reports 6 (1): $35755-35755$.

Wing, O.E., P.D. Bates, A.M. Smith, C.C. Sampson, K.A. Johnson, J. Fargione, and P. Morefield. 2018. Estimates of present and future flood risk in the conterminous United States. Environmental Research Letters 13(3): 034023.

Winsemius, H.C., B. Jongman, T.I.E. Veldkamp, S. Hallegatte, M. Bangalore, and P.J. Ward. 2018. Disaster risk, climate change, and poverty: assessing the global exposure of poor people to floods and droughts. Environment and Development Economics 23 (3): 328348.
Open Access This chapter is licensed under the terms of the Creative Commons Attribution 4.0 International License (http:// creativecommons.org/licenses/by/4.0/), which permits use, sharing, adaptation, distribution and reproduction in any medium or format, as long as you give appropriate credit to the original author(s) and the source, provide a link to the Creative Commons license and indicate if changes were made.
The images or other third party material in this chapter are included in the chapter's Creative Commons license, unless indicated otherwise in a credit line to the material. If material is not included in the chapter's Creative Commons license and your intended use is not permitted by statutory regulation or exceeds the permitted use, you will need to obtain permission directly from the copyright holder. 